Karla Hahn

\title{
New tools for new times \\ Remodeling the scholarly communication system
}

This is not the end. It is not even the beginning of the end. But it is, perhaps, the end of the beginning."-Speech given by Winston Churchill at the Lord Mayor's Luncheon, Mansion House, London, November 10, 1942.

W hen I think about the scholarly communication crisis, this quote from Churchill comes to mind. The crisis is far from over, although librarians have been sounding the alarm for quite a while. It's hard not to wonder, "When will it be over?" And yet, looking back, it is remarkable how far we have come over the years. As librarians have come to understand that their difficulties managing skyrocketing demands on their materials budgets reflect problems and new challenges for the system of scholarly communication, we have arrived at this point through quite visionary leadership within the library community.

Over time, the scholarly communication crisis has become a concept that is quite familiar to academic librarians. We have educated ourselves, created change, and tackled a host of issues under the scholarly communication umbrella. After instituting scholarly communication capabilities, both the Association of Research Libraries (ARL) and ACRL have recently committed to increasing their support and activity levels in the arena. Clearly we believe that much, much more needs to be done. I think this is why the Churchill quote comes to mind so readily, particularly his words, "But it is, perhaps, the end of the beginning."

Surveying all of the work underway in library associations and academic librar- ies, it seems we've passed the beginning. Yet at the same time, many institutions are starting afresh to organize a new set of activities based on a richer understanding of how much is involved in change and how much change is involved. While our need for awareness and ownership continues, we are increasingly engaged in activism and transformation of scholarly communication practices. ${ }^{1}$ The scholarly communication system is now clearly undergoing a major remodeling project and no one has a complete set of blueprints for the new structure.

The tools that helped us launch our initial conversations about the issues, particularly with faculty, are becoming worn, too familiar, and overused. Our language for talking about scholarly communication is maturing as our understanding of the issues changes. We recognize the need to speak about the issues with stakeholders who have different perspectives to offer. Our tools have evolved to reflect the maturation in thought, approach and perspective.

Both ARL and ACRL maintain general scholarly communication pages reflecting the associations' activities, targeted mainly at librarians, that regularly offer new resources created through association activities. For instance, ARL recently published a SPEC Survey on institutional repositories surveying their deployment at research libraries. It provides a cogent summary of the state

Karla Hahn is director of the office of scholarly communication for the Association of Research Libraries, e-mail: karla@arl.org

(c) 2006 Karla Hahn 
of the art, and includes many policy and practice documents. The ACRL Scholarly Communication Toolkit links together resources for librarians with resources addressing two additional audiences: faculty and campus administrators. It is structured to allow each audience to follow a path of information tailored to its interests. SPARC, the Scholarly Publishing and Academic Resources Coalition, similarly manages a site filled with information regarding scholarly communication issues. It too offers tools for library outreach, most recently to support the Federal Research Public Access Act of $2006^{2}$ and SPARC's Author Rights initiative.

\section{Creating change}

Another important toolset for the library community was developed cooperatively as part of the Create Change initiative, launched in 1999. A partnership between ARL and SPARC with support from ACRL, the initiative produced a scholarly communication Web site and several brochures to describe and explain key issues. The initiative's tools, designed to assist in reaching and educating a faculty audience, were distributed throughout the library community.

The Create Change Web site and its companion brochures proved very popular and heavily used. As the language and issues of scholarly communication discussions evolved, the site responded with regular updates. Reflecting the progress libraries have made in engaging in changing scholarly communication, a completely redesigned Create Change Web site was released in June 2006.

Redesigning the site presented an opportunity to rethink its purpose. Create Change has refocused to addresses the librarian's question, "How can I talk about scholarly communication issues in a way that will resonate with faculty on my campus?" It supports libraries by creating products to speak directly to faculty. The Create Change site, as it is now designed, stimulates discussions between librarians and faculty by presenting a variety of issues framed by the faculty perspective. At many points it uses faculty voices to talk about change.

The site's tagline reads, "Shouldn't the way we share research be as advanced as the Internet?" Examples of productive changes in communication and research practices are drawn from a wide range of disciplines. The site shows that change is well underway and that research and scholarship are already experiencing the benefits. The present state of scholarly communication provides the point of departure for considering the potential of future change-provided that faculty act to ensure their needs and concerns are addressed.

\section{ACRL scholarly communication toolkit}

The toolkit (www.ala.org/ala/acrl/acrlissues /scholarlycomm/scholarlycommunicationtoolkit/), which debuted in March 2005, supports advocacy efforts toward changing the scholarly communication system. It summarizes key issues and content to give quick, basic information on scholarly communication topics.

Tools include:

- Coming soon: Glossary of key terms

- Selective bibliography.

- Webliography of online exhibits, sample publishing agreements, directories, price data and more.

- Presentations and brochures created by librarians, which you can adapt for local use.

Your contributions needed

The toolkit is a living site with revised content and new tools as issues change. The ACRL Scholarly Communications Committee encourages you to submit your tools and suggestions to Kara Malenfant,ACRL's scholarly communications and government relations specialist, at kmalenfant@ala.org.

The toolkit serves as a model for collegial sharing. Those wishing to submit materials are strongly encouraged to include a Creative Commons license. 
Create Change highlights issues researchers care about as authors and readers-"Is my work finding its best and fullest audience? Can I easily obtain all of the information I need?" The site avoids presenting change in scholarly communication as a solution to library budget problems or an opportunity to save money. Instead, issues are framed in terms of their significance for advancing research and scholarship and their direct effects on faculty members' daily work.

Interviews with pioneering faculty and researchers present the views of scholars deeply engaged in research and teaching. Each discusses his or her personal observations of what is happening in the scholarly communication system and offers opinions on how the future might look.

Faculty voices are also clear in a section called "Distress Signals." It provides examples of thoughts that may have recently passed through a faculty member's mind. For instance, "I get access to lots of journals through the Internet, but I can't get access to some journals I need. Why doesn't the system work better?"

\section{Scholarly communication tools}

- ACRL Scholarly Communication Initiative: www.ala.org/ala/acrl/acrlissues/ scholarlycomm/scholcomminitiative.htm

- ACRL Scholarly Communication Tool Kit: www.ala.org/ala / a crl/acrlissues/s cholarlycom m /scholarlycommunicationtoolkit/

- ARL Office of Scholarly Communication: www.arl.org/osc/index.html

- ARL Spec Kit, “SP292 Institutional Repositories"-Executive Summary: www.arl.org/spec/SPEC292web.pdf

- Create Change: www.createchange. org

- SPARC: www.arl.org/sparc/

- SPARC's work for public access is available from the Alliance for Taxpayers: Www.taxpayeraccess.org

- SPARC's Author Rights initiative: Www.arl.org/sparc/author/index.html
The site's simple design will facilitate updates as time passes. Already, new interviews are being developed to represent more disciplines and voices, while other adjustments are being made as librarians offer suggestions. While the new Create Change site is designed to enable easy scanning, it does not skimp on the details. Its pages offer rich and deep exploration of relevant issues and essential information to librarians as well as its faculty audience. The style of the presentation, the many examples, and the words of scholars speaking about their personal experiences with change provide new ideas for initiating dialogue and engagement at any institution.

Libraries appear in Create Change in many contexts. They are presented as partners in most of the model programs mentioned on the site. Faculty members are encouraged to work with their libraries in the "Stay Informed" section, and librarians are recognized as leaders in staying abreast of scholarly communication developments.

The new direction for the Create Change Web site is just one step in the continuing evolution of tools to support change in the system of scholarly communication. The joint ACRL/ARL Institute on Scholarly Communication, launched with an immersive learning event in July 2006, will expand in the coming months to include new resources to assist the development of faculty outreach programs around scholarly communication. The institute will continue to evolve and offer learning events that use a competitive application process, but it will also generate publicly accessible resources.

The increasing diversity and sophistication of the tools librarians are using to support faculty outreach demonstrate how quickly we have moved in recent years. The commitment of the academic library community to continuing engagement with these issues is abundantly clear. The ongoing evolution of librarians' understanding of the possibilities and challenges presented by new models of scholarly communication will continue to

(continued on page 614) 
a retreat. A small group developed outcomes, agenda, and appropriate activities. Wonderful, amusing life-size drawings of the "freshman of the future," fully wired and wireless, of course, emerged and helped to inform their discussion of service needs. Ten years ago, we may very well have hired a consultant to assist the group.

\section{Change over the long term}

The effects of a staff development and training program on a large organization are gradual and will only happen with sustained effort and consistent attention. It is tempting to deliver short, intense blasts of training aimed at an organizational problem or a group of employees. Patience, persistence and repetition, however, are the keys to engendering change and unlocking the potential within library staff members.

\section{Notes}

1. Jerry B. Harvey, The Abilene Paradox and Other Meditations on Management (San Francisco: Jossey-Bass, 1988).

2. Lois B. Hart, Faultless Facilitation, 2nd ed. (Amherst, MA: HRD Press, 1996).

3. George J. Soete, 2000. The Library Meeting Survival Guide (San Diego: Tulane Street Publications, 2000). $\approx$
("New tools ...," cont. from page 610)

reshape many of our tools and provide opportunities to develop new ones.

\section{Notes}

1. The evolution of scholarly communication programs through stages of awareness, understanding, ownership, activism, and transformation are presented in Joyce L. Ogburn, "Defining and Achieving Success in the
Movement to Change Scholarly Communication." LRTS, Library Resources and Technical Services, forthcoming.

2. The Federal Research Public Access Act of 2006 was discussed in a previous scholarly communication column. Ray English and Peter Suber, "Public Access to Federally Funded Research: The Cornyn-Lieberman and Cures Bills," CERL News 67, no. 6 (2006). n

\section{Statement of ownership and management}

College E Research Libraries News is published 11 times a year (monthly, combining July/August) by the American Library Association, 50 E. Huron St., Chicago, IL 60611. American Library Association, owner; Stephanie Orphan, editor. Second-class postage paid at Chicago, Illinois. Printed in the U.S.A.As a nonprofit organization authorized to mail at special rates (DMM Section 423.12), the purposes, function, and nonprofit status of this organization and the exempt status for federal income tax purposes, have not changed during the preceding 12 months.

Extent and nature of circulation. ("Average" figures denote the number of copies printed each issue during the preceding twelve months; "Actual" figures denote the number of copies of single issues published nearest to filing date.) Total number of copies (net press run): Average, 14,553; Actual, 14,237. Total paid/requested subscriptions:
Average, 13,574; Actual, 13,250. Sales through dealers and carriers, street vendors, counter sales, and other non-USPS paid distribution: not applicable. Other classes mailed through the USPS: not applicable. Total paid and/or requested circulation:Average, 13,574 Actual, 13,250. Free distribution by mail: Average, 71; Actual, 101. Free distribution outside the mail: Average, 0; Actual, 0. Total free distribution:Average, 71;Actual, 101.Total distribution: Average, 13,645; Actual, 13,351. Copies not distributed: Office use, leftover, spoiled:Average, 908; Actual, 886. Total (sum of previous entries): Average, 14,553; Actual, 14,237. Percent paid and/or requested circulation:Average, 99.48\%;Actual, 99.24\%.

Statement of ownership, management, and circulation (PS Form 3526, October 1999) for 2005 filed with the United States Postal Service, Postmaster in Chicago, Illinois, September 29, 2006. 